In the energy sector, for example, the statistics rely on imperfect estimates of, say, the amount of fuel moving through a pipe or leaking out of a valve. Emissions also vary from one chunk of coal to another, according to their origins, as well as among different kinds of crude oil. Outside the energy sector, the challenges are even more complex. Agricultural emissions vary from crop to crop and from farm to farm, and there is no single equation for estimating carbon uptake by forests. The further one digs down into the data, the more uncertainties one encounters.

So what should be done? The US National Research Council tackled this question in a report issued in March, laying out a roadmap that could — and should - be implemented relatively cheaply over the next few years. The first task is to improve emissions inventories. At present, industrialized nations are required to report their annual emissions data to the United Nations each year, but these data need to be broken down by time, region and, as far as possible, by facility. Major developing countries would then need to be phased into this same system.

These inventories are calculated using government and industry data. However, given the high economic stakes, even the most thorough such reporting will not suffice as evidence about which nations are and are not living up to their commitments. These emissions numbers will need to be independently verified with an expanded network of atmospheric measurements. To accomplish this, governments should extend and improve their verification efforts by increased monitoring of major facilities, cities and agricultural areas, as well as by supporting a global monitoring capability from space.

Europe is making progress in this direction with a planned groundbased Integrated Carbon Observation System that could be rolled out within a few years, but efforts are needed around the world. Where satellites are concerned, the outlook is encouraging, although frustratingly slow. Japan is collecting initial data from GOSAT, its satellite for observing greenhouse gases; NASA, meanwhile, is pushing forward with a second Orbiting Carbon Observatory after losing the first during launch last year.

All of these efforts need to be continued, strengthened and expanded. The specifics of who pays and how the data-gathering is managed will doubtless be hammered out over time, and may well have to be included in whatever international climate treaty finally emerges. But regardless of how the details play out, it's clear that those policing any such treaty will need a much more sophisticated monitoring system than the ad-hoc version in use today.

\section{Open to all}

\section{A new approach to technology assessment would supplement expert opinion with input from society.}

E ver since 1995, when a then-new Republican majority voted to close the US Congress Office of Technology Assessment (OTA) on the grounds that it wasn't necessary, calls have been made for its revival. Many say that the closure was short-sighted. Congress, like legislatures and executives in other nations, sorely needs a way to assess the complex scientific and technical issues involved in subjects such as climate change or genetically modified organisms.

But anything that replaces the OTA will need to confront some marked changes to the political environment that prevailed two decades ago. Then, the OTA's stock in trade was expertise, with about 150 professional staff members marshalling the best available technical information to produce authoritative reports.

Today, by contrast, the public and politicians alike are considerably less willing to accept the consensus of 'experts', even when it comes to technically grounded policy questions. The dominant strain in American domestic politics, as manifested in President Barack Obama's marshalling of grass-roots activists during his 2008 election campaign, and in the more recent 'Tea Party' movement against 'big' government, is a hunger for direct participation.

Reinventing Technology Assessment, a 2010 report from the Woodrow Wilson International Center for Scholars in Washington DC that lays out a new vision for US technology assessment, points to recent international experience, particularly in Europe, and calls for a broader, 'participatory technology assessment' (pTA) model that would supplement expert opinion with early input from all corners of society.

Such a model might have helped the US government to avoid spending 30 years and US $\$ 9$ billion to develop the Yucca Mountain nuclear waste repository in Nevada, only for Obama to abandon the project last year in deference to local opposition. As National Academy of Sciences studies of risk assessment have inferred, it would have been wiser and cheaper to interact with the public at the beginning of the project, rather than at its end.

Whatever the virtues of the pTA approach, however, it is likely to be tricky to implement. If the process is to be credible to the public, for example, it will have to be open and transparent. Yet the doors cannot be thrown open to anyone who shows up at a meeting; that would make the process vulnerable to manipulation by specialinterest groups, which have become adept at drumming up phony 'astroturf' grass-roots movements and spreading misinformation to inflame public opinion. Instead, the pTA organizers would have to do a careful job of recruiting representative samples of citizens, and motivating them to participate - presumably by paying them.

For decision-makers to listen, a pTA approach would have to be integrated with existing advisory mechanisms. One possibility would be to assign pTA responsibilities to well-established organizations such as Congress's Government Accountability Office, or the independent National Academies. Another possibility, advocated by the Wilson Center report, would be to create a non-governmental Expert and Citizen Assessment of Science and Technology network, which would include organizations with experience in public outreach such as non-partisan policy research institutions, universities and science museums.

Whatever its institutional form, however, the pTA approach needs to be attempted. It is exactly what Congress needs as it grapples with complex technical issues, and is squarely in line with the stated objective of Democrat and Republican politicians to build wider public participation in decision-making. All that's required is for Congress itself to agree, on a bipartisan basis, to set it up. 